http://www.jfas.info

\title{
CLASSIFICATION OF LUBRICANT OIL ADULTERATION LEVEL USING CASE-BASED REASONING
}

\author{
S. M. Daud, M. S. Najib , N. Zahed, M. F. M. Jusof, M. F. C. Jusoh@Yusoff and M. I. I. N. \\ Hassim
}

Faculty of Electrical and Electronics Engineering, Universiti Malaysia Pahang, 26600 Pekan, Pahang, Malaysia

Published online: 05 October 2017

\begin{abstract}
The main purpose of this paper is to classify lubricant oil odor-profile using Case-based Reasoning classifier. Electronic nose was used for the purpose of taking data readings for each lubricant oil smell sample. The data that have been collected will be normalized, so that the data can be evaluated in a smaller scale to establish an odor-profile for each sample. Then, the odor-profiles were classified using Case-based Reasoning (CBR) classifier. The classification performance resulting $100 \%$ successfully correct classification.
\end{abstract}

Keywords: lubricant oil; odor-profile; electronic nose; case-based reasoning.

Author Correspondence, e-mail: sharfi@ump.edu.my

doi: http://dx.doi.org/10.4314/jfas.v9i4s.15

\section{INTRODUCTION}

The automotive industry is considered as one of the largest manufacturing sectors in the world [1]. This beneficial sector includes several significant branches which are suspension system, fuel consumption, materials and lubricant oil as well [2-5]. Lubricating oil is one of the products of petroleum refinery and it is one of the largest areas of research and innovation in the automotive sector [6]. Lubricating oil is very important in order to keep the engine 
operating at peak performance level and protect it from the effects of heat by cooling the engine, reducing friction between two moving parts and avoiding the entry of contaminants [7-9]. The analysis on lubricant oil need to be performed in order to control and monitor the quality of lubricant oil in the market.

There were many analysis techniques used for lubricant oil analysis. Some of them are ICP-OES, AAS and ICP-MS [10-13]. These instruments are powerful tools that widely used in chemical laboratories for analyzing trace metals in lubricant oil samples [14]. However, analysis using these tools have several limitations on the complexity of the experimental procedure, high cost and only trained chemist can operate these instruments. Because of that, electronic nose was chosen as the alternative way to determine and analyze the degradation level of lubricant oil samples based on the odor-profile in order to overcome the limitations that occurred in the existing method.

Electronic nose is a useful instrument for various odor identification, degree of aroma intensity and the level of adulteration [15]. E-nose consist of a sensor array that provides odor data reading in resistance value [16-17]. The usage of e-nose in automotive industry is a significant approach in order to control its quality and performance [18]. Thus, the classification of lubricant oil based on odor-profile using electronic nose is very useful with the combination of case-based reasoning classification algorithm in the e-nose system.

Case-based Reasoning (CBR) is an approach to solve problems by using the past cases and experiences by comparing the similarity percentage with the current cases [19]. The current case of the sample is compared with the database consisting of specific similarity calculation [20]. CBR can provide good classification solutions and suitable for a weak domain field. Compared to other classification techniques, CBR does not have data splitting ratio for training and testing data. CBR reuses the previous solution or past experience in order to solve current problems [19].

CBR technique applies 4 cyclical processes which are retrieving, reusing, revising and retaining [21]. The retrieval process is the initial approach in CBR. It requires determining the key parameters to be used to find the correspond target cases with similar existing cases, determining the values of the key parameters of the target, and determining which of the existing cases have values of the key parameters that are similar to the target case [22]. In reuse cycle, CBR system will use old stored data which denotes that the most similar case is chosen as the best solution [23]. Revise and adjust the most comparable case or gathering of cases as fitting if an immaculate match is not found [24]. Retaining the new solution as a part 
of the new case and it is very useful for future problem solving by keeping the experience in memory solving new problems in the future [25].

This paper presents a significant classification technique of lubricant oil adulteration level based on odor-profile using e-nose instrument and case-based reasoning classifier. E-nose was used to collect the odor data in order to establish the odor-profile of the lubricant oil samples. Then, the classification process takes place by using CBR classifier.

\section{METHODOLOGY}

Fig. 1 shows the overall flowchart for the study of lubricant oil degradation level classification based on odor-profile using CBR. The process starts with collecting raw data using e-nose hardware. Next, data pre-processing was made by using normalization and mean calculation technique. Then, the features were extracted from each oil sample in order to establish the odor-profile. Afterwards, the odor-profile were then classified using the CBR classification technique. Lastly, the performance of classification result will be evaluated in order to determine the overall sensitivity, specificity and accuracy of the classification system for lubricant oil samples.

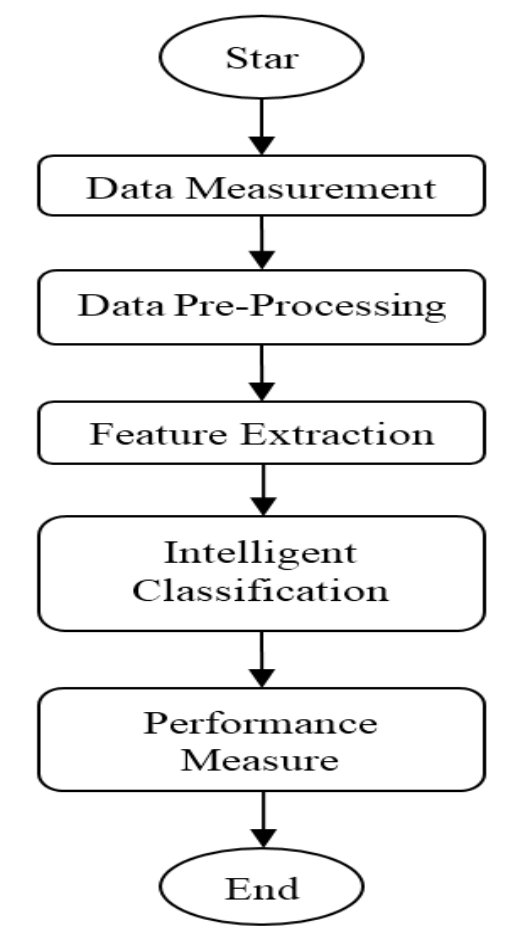

Fig.1. Overall flowchart for lubricant oil odour-profile classification

\subsection{E-Nose Experimental Setup and Data Measurement}

Electronic nose was used to collect lubricant oil odor data. This instrument consists of a chemical sensor array, odor chamber, e-nose pump and microcontroller. Type of lubricant oil 
used for this study is from semi-synthetic type, which is 5W/40. Mostly car owner in Malaysia consume this type of oil due to its affordable price. A specific type of engine was used for a specific regular car. The lubricant oil samples consist of 4 different levels of degradation based on car mileage which are $0 \mathrm{KM}, 1000 \mathrm{KM}, 2000 \mathrm{KM}$ and $3000 \mathrm{KM}$. $0 \mathrm{KM}$ is the virgin oil, while the other rest oil samples are the used oils that taken from the car engine.

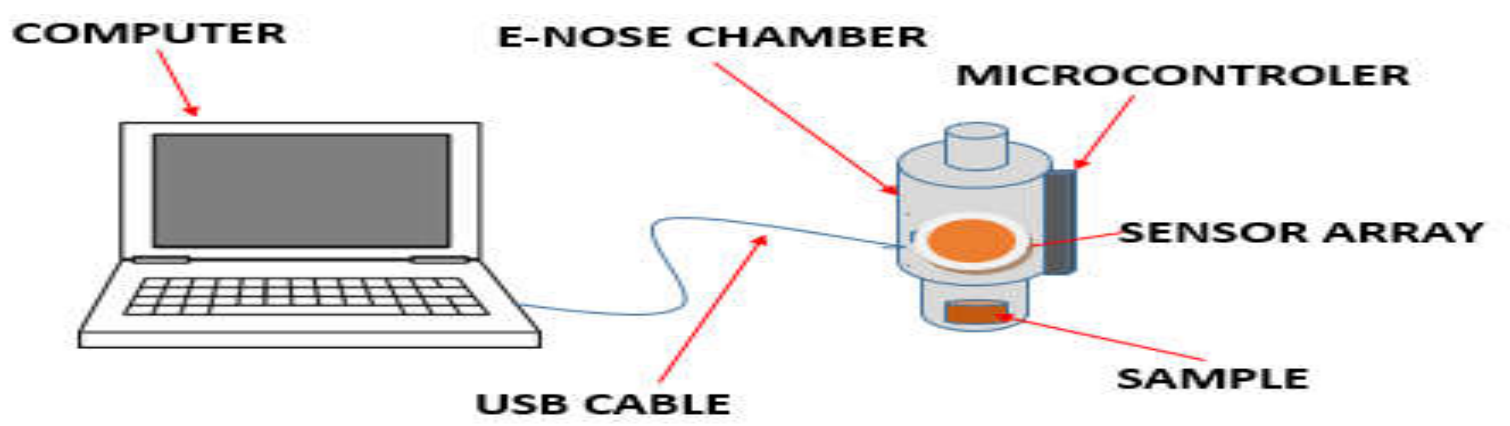

Fig.2. Electronic nose experimental setup

Fig. 2 shows the experimental setup for lubricant oil odor data measurement. A volume of $3 \mathrm{~mL}$ of each lubricant oil sample was taken and placed in sample dish for odor data reading. $3 \mathrm{~mL}$ of lubricant oil sample is the standard sample volume in this electronic nose test and it is already volatile and suitable to the size of sample dish. The pump that is located inside the upper part of e-nose sucks in the odor into the e-nose chamber and the sensor array took the data reading of lubricant oil odor that has accumulated inside the chamber. The data were then sent to a computer via USB cable.

For every experimental session, 2 minutes were spent for data collection. Within 2 minutes, 200 data measurements were able to be collected and the data measurement is very consistent. 5 repeated experiments was done for every sample. The raw data collected will then be tabulated in Table 1.

Table 1. Data measurement table for lubricant oil odor-profile

\begin{tabular}{ccccc}
\hline Data Measurement & S1 & S2 & S3 & S4 \\
\hline 1 & $\mathrm{DM}_{11}$ & $\mathrm{DM}_{12}$ & $\mathrm{DM}_{13}$ & $\mathrm{DM}_{14}$ \\
2 & $\mathrm{DM}_{21}$ & $\mathrm{DM}_{22}$ & $\mathrm{DM}_{23}$ & $\mathrm{DM}_{24}$ \\
3 & $\mathrm{DM}_{31}$ & $\mathrm{DM}_{32}$ & $\mathrm{DM}_{33}$ & $\mathrm{DM}_{34}$ \\
$\cdot$ & $\cdot$ & $\cdot$ & $\cdot$ & $\cdot$ \\
$\cdot$ & $\cdot$ & $\cdot$ & $\cdot$ & $\cdot$ \\
$\cdot$ & $\cdot$ & $\cdot$ & $\cdot$ & $\cdot$ \\
1000 & $\mathrm{DM}_{10001}$ & $\mathrm{DM}_{10002}$ & $\mathrm{DM}_{10003}$ & $\mathrm{DM}_{10004}$ \\
\hline
\end{tabular}


In the table above, 1000 data measurement was collected from 5 repeated experiments for every sample. S1, S2, S3 and S4 indicates the sensor 1, sensor 2, sensor 3 and sensor 4 respectively. DM represents the data measurement of lubricant oil samples.

\subsection{Data Pre-Processing}

The raw data that were collected before, were normalized by using Equation (1). To get the normalized values, every row of the raw data measurement need to be divided with the highest value from its own row. Thus, the value will be rescaled into smaller value in the range between zeros to one (0-1). 0 and 1 value are the minimum and maximum value respectively for the normalized data. The normalized value is very useful for odor-profile extraction. The values were then tabulated into Table 2 .

$R^{\prime}=\frac{R}{R_{\max }}$

Table 2. Data normalization table for lubricant oil odor-profile

\begin{tabular}{ccccc}
\hline Normalized Data & S1 & S2 & S3 & S4 \\
\hline 1 & $\mathrm{ND}_{11}$ & $\mathrm{ND}_{12}$ & $\mathrm{ND}_{13}$ & $\mathrm{ND}_{14}$ \\
2 & $\mathrm{ND}_{21}$ & $\mathrm{ND}_{22}$ & $\mathrm{ND}_{23}$ & $\mathrm{ND}_{24}$ \\
3 & $\mathrm{ND}_{31}$ & $\mathrm{ND}_{32}$ & $\mathrm{ND}_{33}$ & $\mathrm{ND}_{34}$ \\
$\cdot$ & $\cdot$ & $\cdot$ & $\cdot$ & $\cdot$ \\
$\cdot$ & $\cdot$ & $\cdot$ & $\cdot$ & $\cdot$ \\
$\cdot$ & $\cdot$ & $\cdot$ & $\cdot$ & $\cdot$ \\
1000 & $\mathrm{ND}_{10001}$ & $\mathrm{ND}_{10002}$ & $\mathrm{ND}_{10003}$ & $\mathrm{ND}_{10004}$
\end{tabular}

Table 2 shows the data normalization table for lubricant oil sample. The normalized data consists of 1000x4 data. S1, S2, S3 and S4 represent sensor 1, sensor 2, sensor 3 and sensor 4 respectively. ND represents the normalized data of the lubricant oil sample.

\subsection{Feature Extraction}

From the normalized value, the features of each sample were extracted. The normalized value will be clustered into groups of oil degradation level. In each group, 10 cases were obtained from the mean calculation of the normalized value. The cases of each group were tabulated and stored into CBR memory as "stored cases" or the "previous experiences" for the classification process.

\subsection{Intelligent Classification}

Case-based Reasoning (CBR) is one of the well-known classifier technique used in classification. CBR consists of 4 main cycles that needs to be followed in order to perform 
classification which are retrieve, reuse, revise and retain. Fig. 3 shows the cycles of CBR for lubricant oil classification.

The cycle shown in Fig. 3 starts with the unknown lubricant oil that represent the test sample. The odor-profile from the unknown oil sample went through the retrieval phase to retrieve the stored cases inside the memory. Since CBR is learning from previous cases, the system compares the unknown odor-profile oil sample with the stored odor-profile of previous cases. If the unknown sample has high similarity percentage with stored oil sample, the system will reuse the information from stored case to give a decision or answer. This classification technique very different than other classification technique (ANN, K-NN) because this technique require no data training.

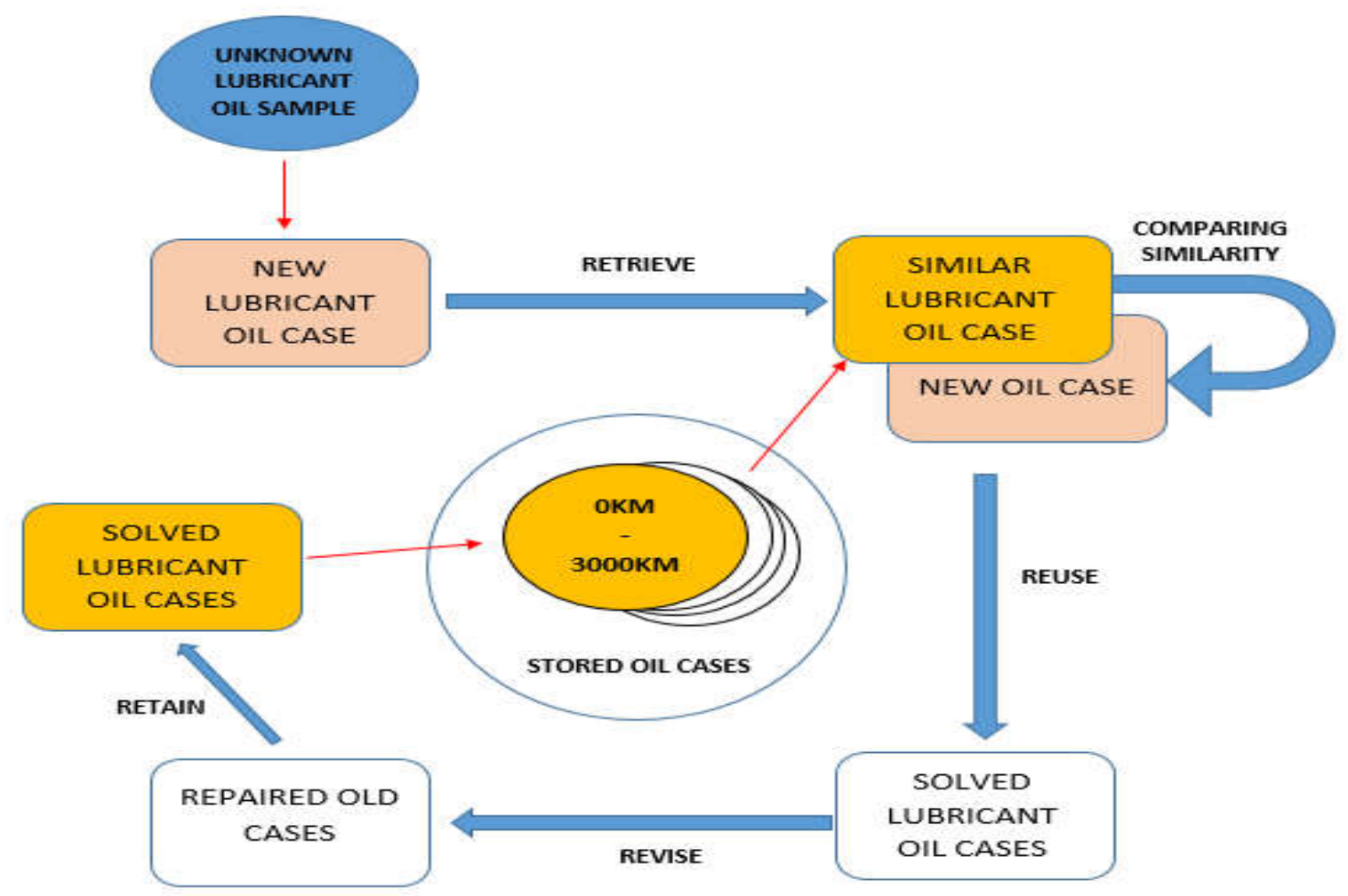

Fig.3. CBR cycle for lubricant oil odor-profile classification

To calculate the similarity percentage between 2 cases in the CBR retrieval cycle, one case out of 40 stored cases was picked for the calculation. Then, the remaining 39 cases are left as the rest stored cases. Equation (2) was used to formulate the similarity percentage. If the percentage of similarity is the highest between two cases, it means that the distance between the two cases is near and they come from the same group. 
$\operatorname{Similarity}(T, S)=\frac{\sum_{i=1}^{n} f\left(T_{i}, S_{i}\right) \times w_{i}}{\sum_{i=1}^{n} w_{i}}$

In this equation, $\mathrm{T}$ and $\mathrm{S}$ represent the target case and source case respectively, $\mathrm{n}$ is the number of attribution for lubricant oil sample, $i$ is the single attribution for each case, $f$ is the similarity function formulation for lubricant oil sample and w represents the weight of each attribution.

\subsection{Performance Measure}

The CBR Classification result was evaluated using confusion matrix. Equation (3)-(5) was used in order to calculate sensitivity, specificity and accuracy of overall lubricant oil sample classification process.

$$
\begin{aligned}
& \text { Sensitivity }=\frac{T P}{T P+F N} \\
& \text { Specificity }=\frac{T N}{F P+T N} \\
& \text { Accuracy }=\frac{T P+T N}{P+N}
\end{aligned}
$$

The sensitivity of the classification was calculated by dividing true positive value of classification result with the summation of true positive (TP) and false negative (FN) of the classification. The specificity of the classification was calculated by dividing true negative (TN) with the summation of false positive (FP) and true negative (TN). While, for the accuracy of the classification was calculated by dividing the summation of true positive and true negative with total case $(\mathrm{P}+\mathrm{N})$.

$\mathrm{P}, \mathrm{N}, \mathrm{TP}, \mathrm{TN}, \mathrm{FP}$ and FN in this study focus on the result of CBR voting process. For TP, let say that these cases were predicted 'A', then the actual result is also 'A'. Same concept also applied in TN which were that the cases were predicted ' $\mathrm{B}$ ', then the actual result is also ' $\mathrm{B}$ '. For FP, the predicted result is ' $A$ '. However, the actual result is ' $\mathrm{B}$ ' and same goes to FN. The predicted results were ' $\mathrm{B}$ ', but the actual result is ' $\mathrm{A}$ '.

The accuracy measurement in this study is performed to measure the performance of the CBR accuracy based on lubricant oil samples and how often the correct classification occurs. By other hand, the measurement for sensitivity is calculated the number of "yes" prediction when the case is truly "yes". Next is specificity is evaluated by calculating the total of "No" prediction when the case is actually "No". 


\section{RESULTS AND DISCUSSION}

\subsection{Raw Data Measurement}

For every sample, 5 repeated experiments were performed which were 200 data measurements were collected for each experiment that resulted 1000 data measurement for a sample. Thus, 4000 data measurements that represent for all samples were collected and tabulated.

Fig. 4 shows the graph of raw data measurement against sensor array for 4 lubricant oil sample. Y-axis indicates the raw data measurement which is in resistance value while the $\mathrm{X}$-axis indicates the sensor array. S1, S2, S3 and S4 represent the sensors used in the e-nose. The highest sensor reading for all samples is at sensor S1 while S3 shows the lowest sensor reading for all oil samples. As shown in the figure below, each sample which are 0KM, $1000 \mathrm{KM}, 2000 \mathrm{KM}$ and $3000 \mathrm{KM}$ have slightly similar pattern between each other. Even though the patterns are almost similar, they consist of significant differences between each sample that can be calculated and useful for the classification process. In order to make the pattern more significant, data pre-processing phase need to be performed.

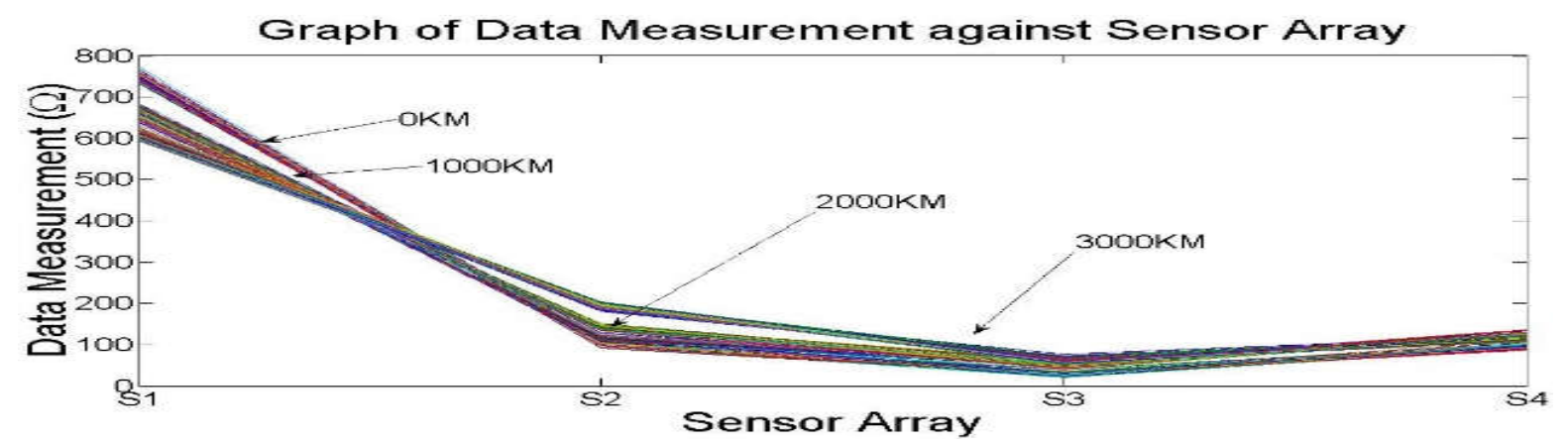

Fig.4. Graph of data measurement against sensor array

\subsection{Data Pre-Processing}

4000 data measurements that collected before were normalized by dividing every value in every row of data measurements with the highest value from its own row. 4000 normalized data then were regrouped into 4 groups that represent each sample. Next, 1000 normalized data per group were clustered into 10 cases. 


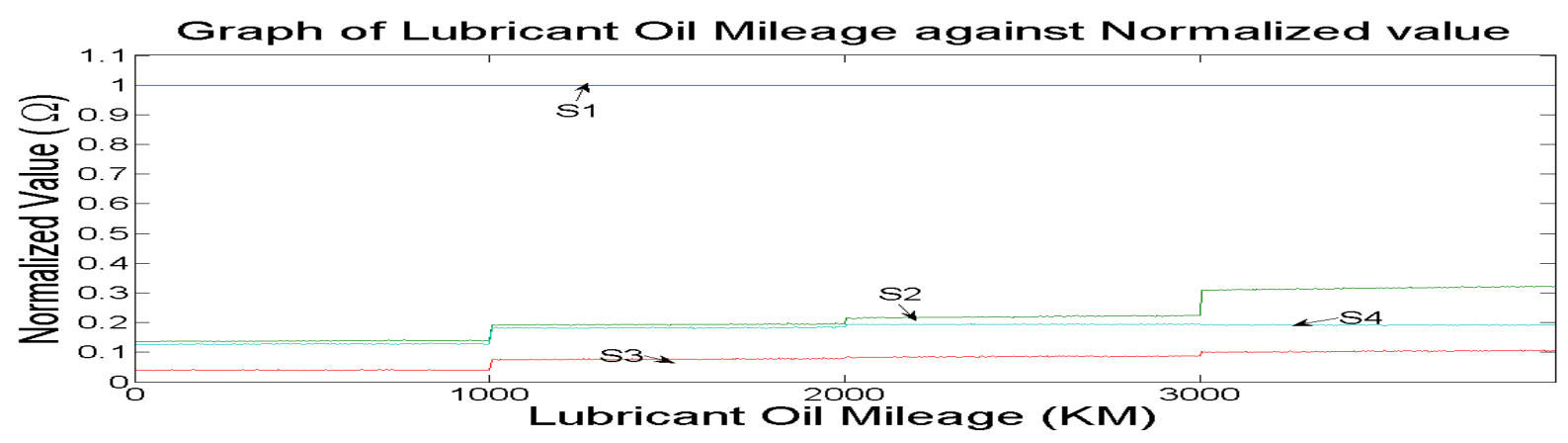

Fig.5. Graph of lubricant oil mileage (KM) against normalized value

Fig. 5 shows the graph of lubricant oil mileage against the normalized value. X-axis indicates the kilometer of the oil that already being used and Y-axis portrays the normalized value of the sensor resistance response. In this graph, 4 lines were plotted that indicated as 4 sensors used in the e-nose. In line S2, S3 and S4, it shows the changes of the normalized value respectively when the oil used in difference mileage. Thus, the lubricant oil odor volatility is increasing when the mileage increase. In other words, when the lubricant oil was used in the engine in the certain mileage, the degree of lubricant oil aroma also changes. The mileage of the lubricant oil influenced the changes of the degree of lubricant oil odor.

Table 3 shows the CBR case library for lubricant oil samples. The table consists of 40 cases that represent 10 cases for every sample. First 10 cases (case_01 until case_10) represent 0KM oil sample. For the next 10 cases, (case_11 until case_20), (case_21 until case_30) and (case_31 until case_40) represent 1000KM, 2000KM and 3000KM lubricant oil sample respectively. S1, S2, S3 and S4 are the sensors used in the e-nose. These cases will act as "stored cases" and will be included into the CBR memory in order to perform classification process.

Table 3. CBR case library for lubricant oil sample

\begin{tabular}{ccccc}
\hline Case ID & S1 & S2 & S3 & S4 \\
\hline Case_01 & 1 & 0.136245 & 0.040054 & 0.127268 \\
Case_02 & 1 & 0.136736 & 0.040381 & 0.127539 \\
Case_03 & 1 & 0.136243 & 0.040287 & 0.127207 \\
Case_04 & 1 & 0.137208 & 0.040539 & 0.127662 \\
Case_05 & 1 & 0.138268 & 0.040084 & 0.127944 \\
Case_06 & 1 & 0.13885 & 0.040376 & 0.128133 \\
Case_07 & 1 & 0.138936 & 0.040704 & 0.128185 \\
Case_08 & 1 & 0.139682 & 0.04058 & 0.127965 \\
Case_09 & 1 & 0.139988 & 0.040396 & 0.128325 \\
\hline
\end{tabular}




\begin{tabular}{|c|c|c|c|c|}
\hline Case_10 & 1 & 0.139552 & 0.040378 & 0.12797 \\
\hline Case_11 & 1 & 0.191581 & 0.074929 & 0.182076 \\
\hline Case_12 & 1 & 0.191957 & 0.075257 & 0.181877 \\
\hline Case_13 & 1 & 0.192289 & 0.075969 & 0.181743 \\
\hline Case_14 & 1 & 0.193006 & 0.075999 & 0.182401 \\
\hline Case_15 & 1 & 0.193019 & 0.076152 & 0.182808 \\
\hline Case_16 & 1 & 0.193638 & 0.076619 & 0.182328 \\
\hline Case_17 & 1 & 0.194079 & 0.077185 & 0.182193 \\
\hline Case_18 & 1 & 0.194666 & 0.077544 & 0.182658 \\
\hline Case_19 & 1 & 0.194951 & 0.07807 & 0.183256 \\
\hline Case_20 & 1 & 0.195185 & 0.078572 & 0.18433 \\
\hline Case_21 & 1 & 0.215316 & 0.083016 & 0.193185 \\
\hline Case_22 & 1 & 0.216123 & 0.083631 & 0.193293 \\
\hline Case_23 & 1 & 0.217388 & 0.08439 & 0.193762 \\
\hline Case_24 & 1 & 0.218604 & 0.084757 & 0.19392 \\
\hline Case_25 & 1 & 0.219081 & 0.085558 & 0.194024 \\
\hline Case_26 & 1 & 0.220262 & 0.085825 & 0.194458 \\
\hline Case_27 & 1 & 0.221356 & 0.086443 & 0.194551 \\
\hline Case_28 & 1 & 0.221518 & 0.08574 & 0.194125 \\
\hline Case_29 & 1 & 0.222138 & 0.086164 & 0.194253 \\
\hline Case_30 & 1 & 0.223213 & 0.087149 & 0.194499 \\
\hline Case_31 & 1 & 0.309065 & 0.100067 & 0.191863 \\
\hline Case_32 & 1 & 0.311163 & 0.100542 & 0.191805 \\
\hline Case_33 & 1 & 0.312436 & 0.101416 & 0.191838 \\
\hline Case_34 & 1 & 0.31346 & 0.101876 & 0.191467 \\
\hline Case_35 & 1 & 0.315238 & 0.103213 & 0.191184 \\
\hline Case_36 & 1 & 0.316334 & 0.103774 & 0.191119 \\
\hline Case_37 & 1 & 0.317918 & 0.103895 & 0.191543 \\
\hline Case_38 & 1 & 0.319203 & 0.104617 & 0.1917 \\
\hline Case_39 & 1 & 0.320212 & 0.104859 & 0.191584 \\
\hline Case_40 & 1 & 0.321379 & 0.105649 & 0.191675 \\
\hline
\end{tabular}

The highest normalized value from this table is in entire column S1 that consist of the value of ' 1 ', while the lowest normalized value is in the whole S3 column for all cases. Only 
column S1 consist of the same value because of the previous raw data were divided with highest value in each row.

Previously, the whole column S1 consist of lubricant oil raw data reading from sensor 1. To obtain normalize data, every row of the data measurement need to be divided with the maximum value of $\mathrm{S} 1, \mathrm{~S} 2, \mathrm{~S} 3$ and $\mathrm{S} 4$.

From the data collection, every row of data measurement has the highest value at column S1. Thus, when then the data measurement was normalized, it was resulting value 1 in column S1 for every row of normalized data. The sensors that set up in the e-nose have different sensitivity. The S1 that represents the sensor 1 have very high sensitivity on lubricant oil samples.

Then, the normalized data were clustered into 10 cases for each sample in order to extract the odor features for each of it.

Fig. 6-9 shows the boxplot for 0KM, 1000KM, 2000KM and 3000KM lubricant oil sample respectively. Each boxplot contains median, first quartile, third quartile, maximum and minimum value. Based on the boxplot for each sensor in each sample, the value of median, first quartile, third quartile, maximum and minimum are very near between each other. It shows that the normalized values for each sensor in each sample are very consistent. Besides that, every median of boxplot for each sensor in each sample have different in value. So, the median for the sensors are significantly different.

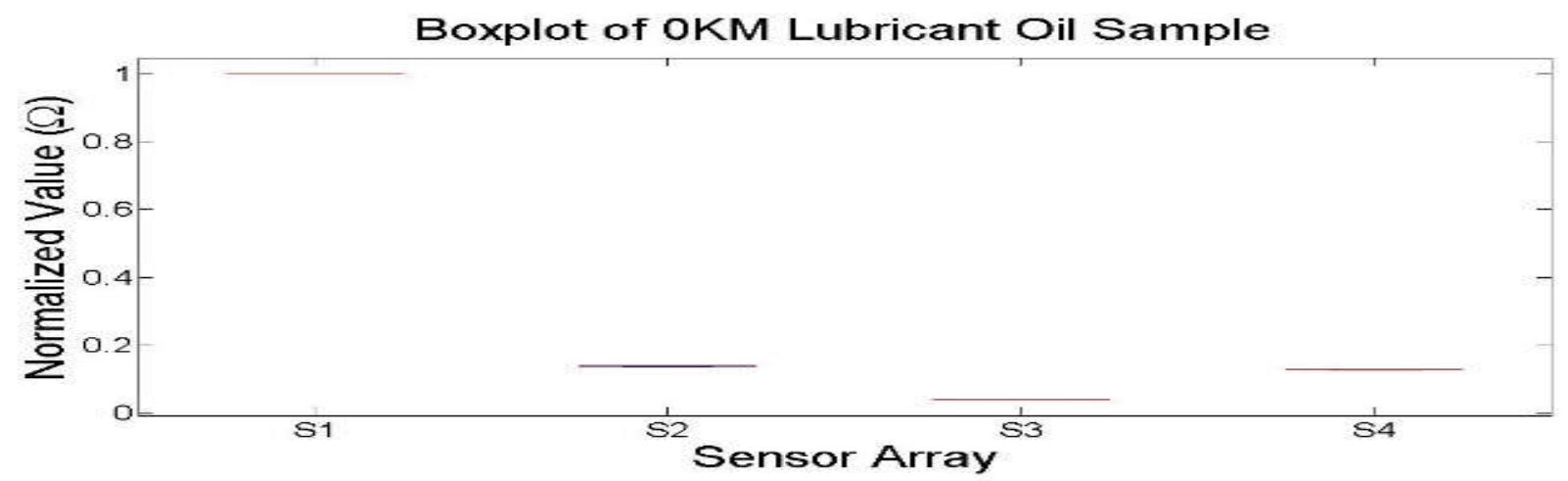

Fig.6. Boxplot of 0KM lubricant sample 


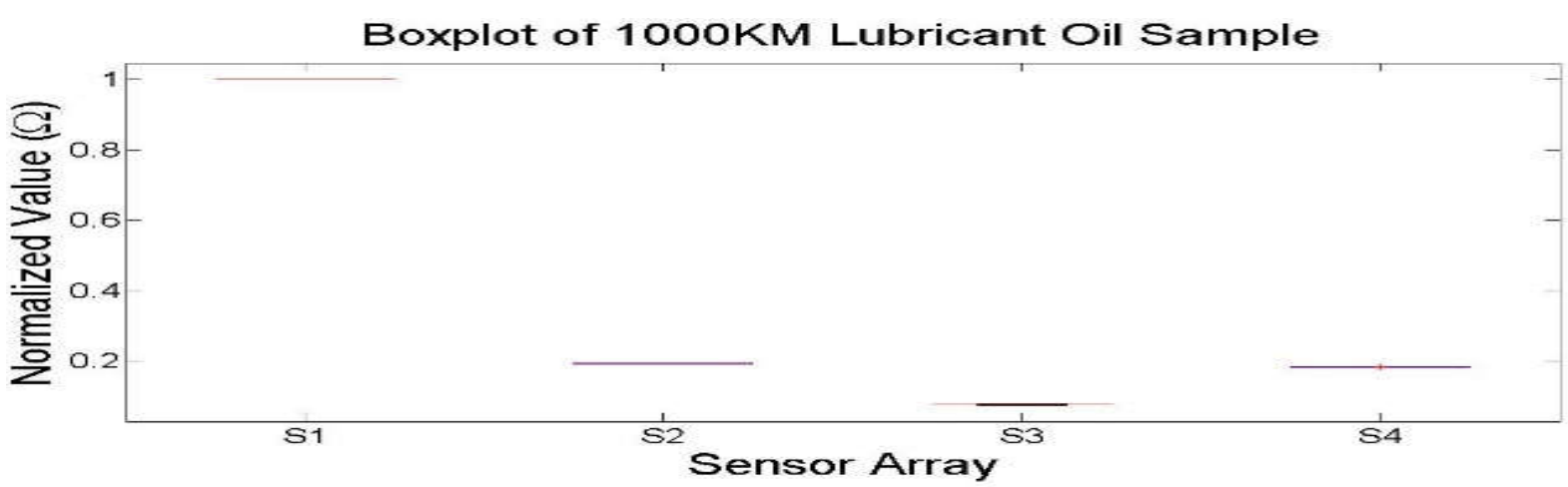

Fig.7. Boxplot of 1000KM lubricant sample

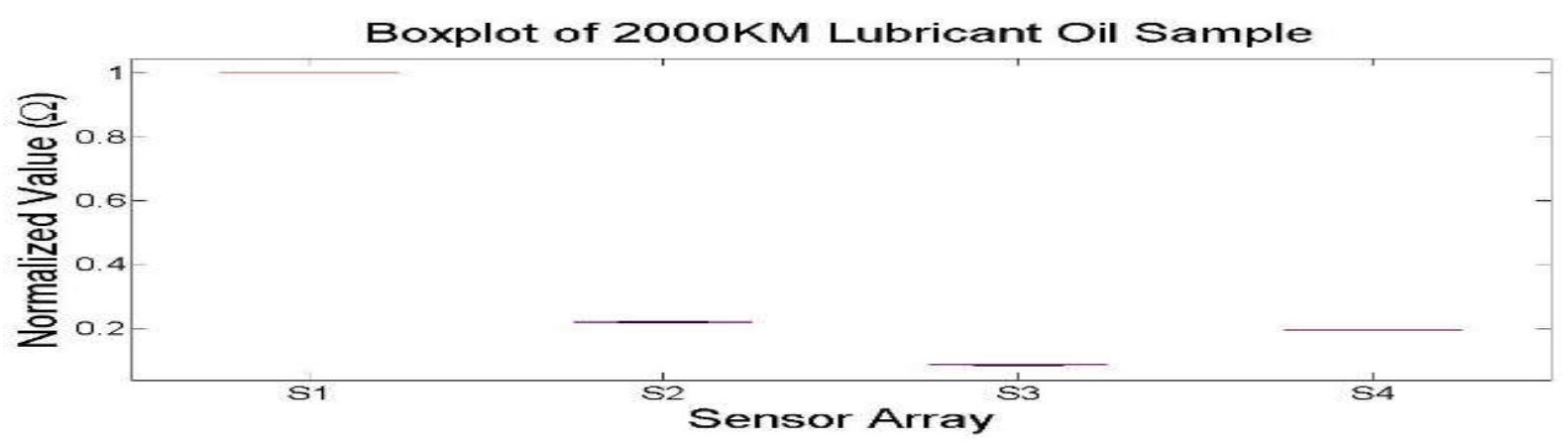

Fig.8. Boxplot of 2000KM lubricant sample

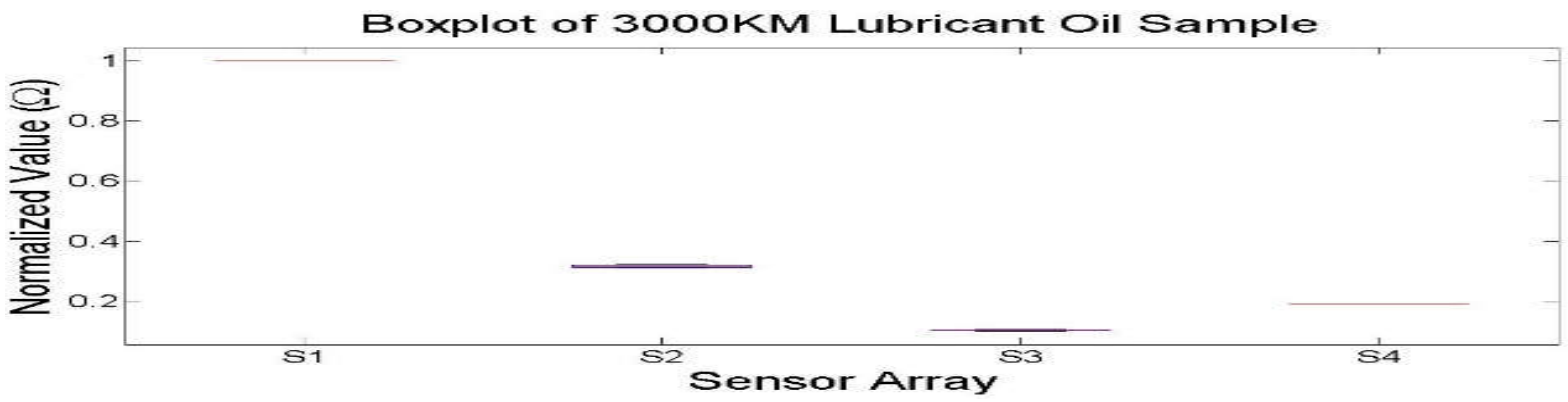

Fig.9. Boxplot of 3000KM lubricant sample

From Table 3, S1 has the highest value which is valued ' 1 '. Since the normalized value of sensor 1 is same for all cases, the values are not very significant for classification because of the similar value for all cases. The value "1" in attire column S1 can be considered as the features for lubricant oil odor-profile. However, by excluding the S1 value, better patterns can be extracted. The pattern of odor-profile by excluding S1 features was plotted as in Fig. 10. 


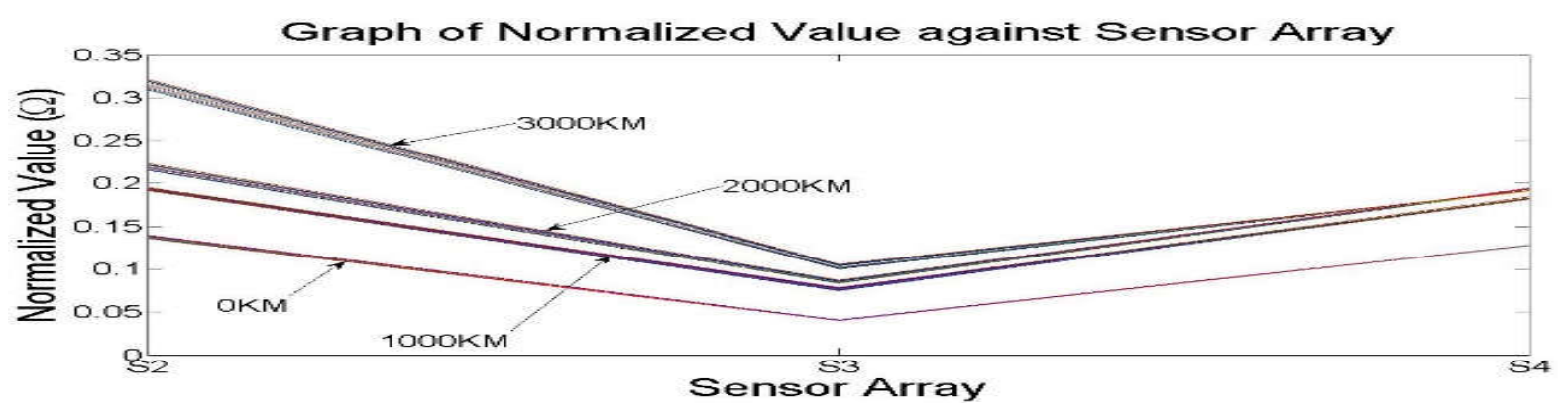

Fig.10. Graph of normalized value against sensor array

Table 4 shows the CBR similarity formulation. Attributes S1, S2, S3 and S4 is the sensor array. The source is the stored case of lubricant oil sample. Target is the current case. The similarity of two cases below is calculated using Equation (2). Normalized weight was calculated by dividing each weight with the total weight. The similarity calculation for every sensor was added in order to obtain the similarity percentage between 2 cases.

Table 4. CBR formulation for one case of lubricant oil samples

\begin{tabular}{ccccccc}
\hline & Source & Target & Sim & w & norm_w & norm_w*sim \\
\hline S1 & 1 & 1 & 1 & 1 & 0.25 & 0.25 \\
S2 & 0.1362 & 0.1367 & 0.9995 & 1 & 0.25 & 0.2499 \\
S3 & 0.0401 & 0.0404 & 0.9995 & 1 & 0.25 & 0.2499 \\
S4 & 0.1273 & 0.1275 & 0.9995 & 1 & 0.25 & 0.2499 \\
\multicolumn{5}{c}{ Total Similarity Between Two Cases } & 0.9997 \\
\hline
\end{tabular}

Table 5 shows the weight vector assignment. The attribute is represented by the sensors used in this e-nose. Local weight value equals to 1 for each sensor was assigned by the expert. In order conduct the odor-profile classification, the expert of lubricant oil need to determine the local weight for each attribution and the value of the weight can be heuristically change in order to get a better classification result. The value of local weight for all attributes was assigned as 1 .

Table 5. Weight vector assignment

\begin{tabular}{cc}
\hline Attribute & Local Weight Value \\
\hline S1 & 1 \\
S2 & 1 \\
S3 & 1 \\
S4 & 1 \\
\hline
\end{tabular}




\subsection{CBR Voting}

Table 6 shows the result of CBR voting for lubricant oil sample classification. The table consists of case ID, expert class, $\mathrm{K}=1, \mathrm{~K}=2$ and $\mathrm{K}=3$. The expert class column was determined by the expert about the oil group. Case 01-case 10, case 11-case 20, case 21-case 30 and case 31 -case 40 represents $0 \mathrm{KM}, 1000 \mathrm{KM}, 2000 \mathrm{KM}$ and $3000 \mathrm{KM}$ lubricant oil sample respectively.

The voting process was performed by arranging the percentage similarity in $40 \times 40$ matrix crossing in the same group and other groups. $\mathrm{K}=1, \mathrm{~K}=2$ and $\mathrm{K}=3$ indicate the highest, second highest and third highest value that were voted in the voting table in each row. All $\mathrm{K}=$ $1, \mathrm{~K}=2$ and $\mathrm{K}=3$ in every row were voted in the same group.

Table 6. CBR voting result

\begin{tabular}{|c|c|c|c|c|}
\hline Case ID & Actual Class & Voting $K=1$ & Voting $K=2$ & Voting $K=3$ \\
\hline Case_01 & $0 \mathrm{KM}$ & $0 \mathrm{KM}$ & $0 \mathrm{KM}$ & 0KM \\
\hline Case_02 & 0KM & $0 \mathrm{KM}$ & $0 \mathrm{KM}$ & 0KM \\
\hline Case_03 & 0KM & $0 \mathrm{KM}$ & $0 \mathrm{KM}$ & $0 \mathrm{KM}$ \\
\hline Case_04 & $0 \mathrm{KM}$ & $0 \mathrm{KM}$ & $0 \mathrm{KM}$ & OKM \\
\hline Case_05 & 0KM & 0KM & 0KM & 0KM \\
\hline Case_06 & $0 \mathrm{KM}$ & $0 \mathrm{KM}$ & $0 \mathrm{KM}$ & $0 \mathrm{KM}$ \\
\hline Case_07 & 0KM & $0 \mathrm{KM}$ & $0 \mathrm{KM}$ & $0 \mathrm{KM}$ \\
\hline Case_08 & $0 \mathrm{KM}$ & $0 \mathrm{KM}$ & $0 \mathrm{KM}$ & $0 \mathrm{KM}$ \\
\hline Case_09 & OKM & OKM & $0 \mathrm{KM}$ & 0KM \\
\hline Case_10 & $0 \mathrm{KM}$ & $0 \mathrm{KM}$ & $0 \mathrm{KM}$ & $0 \mathrm{KM}$ \\
\hline Case_11 & $1000 \mathrm{KM}$ & $1000 \mathrm{KM}$ & $1000 \mathrm{KM}$ & $1000 \mathrm{KM}$ \\
\hline Case_12 & $1000 \mathrm{KM}$ & $1000 \mathrm{KM}$ & $1000 \mathrm{KM}$ & $1000 \mathrm{KM}$ \\
\hline Case_13 & $1000 \mathrm{KM}$ & $1000 \mathrm{KM}$ & $1000 \mathrm{KM}$ & $1000 \mathrm{KM}$ \\
\hline Case_14 & $1000 \mathrm{KM}$ & $1000 \mathrm{KM}$ & $1000 \mathrm{KM}$ & $1000 \mathrm{KM}$ \\
\hline Case_15 & $1000 \mathrm{KM}$ & $1000 \mathrm{KM}$ & $1000 \mathrm{KM}$ & $1000 \mathrm{KM}$ \\
\hline Case_16 & $1000 \mathrm{KM}$ & $1000 \mathrm{KM}$ & $1000 \mathrm{KM}$ & $1000 \mathrm{KM}$ \\
\hline Case_17 & $1000 \mathrm{KM}$ & $1000 \mathrm{KM}$ & $1000 \mathrm{KM}$ & $1000 \mathrm{KM}$ \\
\hline Case_18 & $1000 \mathrm{KM}$ & $1000 \mathrm{KM}$ & $1000 \mathrm{KM}$ & $1000 \mathrm{KM}$ \\
\hline Case_19 & $1000 \mathrm{KM}$ & $1000 \mathrm{KM}$ & $1000 \mathrm{KM}$ & $1000 \mathrm{KM}$ \\
\hline Case_20 & $1000 \mathrm{KM}$ & $1000 \mathrm{KM}$ & $1000 \mathrm{KM}$ & $1000 \mathrm{KM}$ \\
\hline Case_21 & $2000 \mathrm{KM}$ & $2000 \mathrm{KM}$ & $2000 \mathrm{KM}$ & $2000 \mathrm{KM}$ \\
\hline
\end{tabular}




\begin{tabular}{lllll}
\hline Case_22 & $2000 \mathrm{KM}$ & $2000 \mathrm{KM}$ & $2000 \mathrm{KM}$ & $2000 \mathrm{KM}$ \\
Case_23 & $2000 \mathrm{KM}$ & $2000 \mathrm{KM}$ & $2000 \mathrm{KM}$ & $2000 \mathrm{KM}$ \\
Case_24 & $2000 \mathrm{KM}$ & $2000 \mathrm{KM}$ & $2000 \mathrm{KM}$ & $2000 \mathrm{KM}$ \\
Case_25 & $2000 \mathrm{KM}$ & $2000 \mathrm{KM}$ & $2000 \mathrm{KM}$ & $2000 \mathrm{KM}$ \\
Case_26 & $2000 \mathrm{KM}$ & $2000 \mathrm{KM}$ & $2000 \mathrm{KM}$ & $2000 \mathrm{KM}$ \\
Case_26 & $2000 \mathrm{KM}$ & $2000 \mathrm{KM}$ & $2000 \mathrm{KM}$ & $2000 \mathrm{KM}$ \\
Case_27 & $2000 \mathrm{KM}$ & $2000 \mathrm{KM}$ & $2000 \mathrm{KM}$ & $2000 \mathrm{KM}$ \\
Case_28 & $2000 \mathrm{KM}$ & $2000 \mathrm{KM}$ & $2000 \mathrm{KM}$ & $2000 \mathrm{KM}$ \\
Case_29 & $2000 \mathrm{KM}$ & $2000 \mathrm{KM}$ & $2000 \mathrm{KM}$ & $2000 \mathrm{KM}$ \\
Case_30 & $2000 \mathrm{KM}$ & $2000 \mathrm{KM}$ & $2000 \mathrm{KM}$ & $2000 \mathrm{KM}$ \\
Case_31 & $3000 \mathrm{KM}$ & $3000 \mathrm{KM}$ & $3000 \mathrm{KM}$ & $3000 \mathrm{KM}$ \\
Case_32 & $3000 \mathrm{KM}$ & $3000 \mathrm{KM}$ & $3000 \mathrm{KM}$ & $3000 \mathrm{KM}$ \\
Case_33 & $3000 \mathrm{KM}$ & $3000 \mathrm{KM}$ & $3000 \mathrm{KM}$ & $3000 \mathrm{KM}$ \\
Case_34 & $3000 \mathrm{KM}$ & $3000 \mathrm{KM}$ & $3000 \mathrm{KM}$ & $3000 \mathrm{KM}$ \\
Case_35 & $3000 \mathrm{KM}$ & $3000 \mathrm{KM}$ & $3000 \mathrm{KM}$ & $3000 \mathrm{KM}$ \\
Case_36 & $3000 \mathrm{KM}$ & $3000 \mathrm{KM}$ & $3000 \mathrm{KM}$ & $3000 \mathrm{KM}$ \\
Case_37 & $3000 \mathrm{KM}$ & $3000 \mathrm{KM}$ & $3000 \mathrm{KM}$ & $3000 \mathrm{KM}$ \\
Case_38 & $3000 \mathrm{KM}$ & $3000 \mathrm{KM}$ & $3000 \mathrm{KM}$ & $3000 \mathrm{KM}$ \\
Case_39 & $3000 \mathrm{KM}$ & $3000 \mathrm{KM}$ & $3000 \mathrm{KM}$ & $3000 \mathrm{KM}$ \\
Case_40 & $3000 \mathrm{KM}$ & $3000 \mathrm{KM}$ & $3000 \mathrm{KM}$ & $3000 \mathrm{KM}$ \\
\hline
\end{tabular}

\subsection{CBR Performance Measure}

Table 7 shows the confusion matrix for CBR voting results. For every group, $\mathrm{k}=1, \mathrm{k}=2$ and $\mathrm{k}=3$ were voted to be in their own group. The total case for this study is 40 cases. Each oil sample group consists of 10 cases. In confusion matrix table, there is actual case and predicted case. Actual case is the real case of the sample. While for predicted case, it comes from the voting result from Table 6 . In Table 7, it shows that 10 cases for each sample were predicted to be in their group. Thus, total true positive for each group is 10 and the total true positive for all samples is 40 . 
Table 7. Confusion matrix for CBR voting result

\begin{tabular}{cccccc}
\hline & & \multicolumn{4}{c}{ PREDICTED } \\
\multicolumn{1}{c}{ Total Case $=\mathbf{4 0}$} & $\mathbf{0 K M}$ & $\mathbf{1 0 0 0 K M}$ & $\mathbf{2 0 0 0 K M}$ & $\mathbf{3 0 0 0 K M}$ \\
\hline \multirow{4}{*}{ Actual } & 0KM & 10 & 0 & 0 & 0 \\
& $1000 \mathrm{KM}$ & 0 & 10 & 0 & 0 \\
& $2000 \mathrm{KM}$ & 0 & 0 & 10 & 0 \\
& $3000 \mathrm{KM}$ & 0 & 0 & 0 & 10
\end{tabular}

Table 8 shows the performance evaluation for lubricant oil odor-profile classification using CBR classifier. Sensitivity, specificity and accuracy of the classification was calculated using Equation (3)-(5) respectively.

Table 8. CBR performance evaluation

\begin{tabular}{cccc}
\hline Performance Evaluation & $\mathbf{K = 1}$ & $\mathbf{K}=\mathbf{2}$ & $\mathbf{K}=\mathbf{3}$ \\
\hline Total Case & 40 & 40 & 40 \\
0KM Case & 10 & 10 & 10 \\
1000KM Case & 10 & 10 & 10 \\
2000KM Case & 10 & 10 & 10 \\
3000KM Case & 10 & 10 & 10 \\
True 0KM & 10 & 10 & 10 \\
False 0KM & 0 & 0 & 0 \\
True 1000KM & 10 & 10 & 10 \\
False 1000KM & 0 & 0 & 0 \\
True 2000KM & 10 & 10 & 10 \\
False 2000KM & 0 & 0 & 0 \\
True 3000KM & 10 & 10 & 10 \\
False 3000KM & 0 & 0 & 0 \\
Sensitivity 0KM & 1.00 & 1.00 & 1.00 \\
Sensitivity 1000KM & 1.00 & 1.00 & 1.00 \\
Sensitivity 2000KM & 1.00 & 1.00 & 1.00 \\
Sensitivity 3000KM & 1.00 & 1.00 & 1.00 \\
Specificity 0KM & 1.00 & 1.00 & 1.00 \\
Specificity 1000KM & 1.00 & 1.00 & 1.00 \\
Specificity 2000KM & 1.00 & 1.00 & 1.00 \\
Specificity 3000KM & 1.00 & 1.00 & 1.00 \\
\hline & & & \\
\hline & 0 & 000 \\
\hline
\end{tabular}




\begin{tabular}{cccc}
\hline Sensitivity 0KM & 1.00 & 1.00 & 1.00 \\
Sensitivity 1000KM & 1.00 & 1.00 & 1.00 \\
Sensitivity 2000KM & 1.00 & 1.00 & 1.00 \\
Sensitivity 3000KM & 1.00 & 1.00 & 1.00 \\
OVERALL SENSITIVITY & 100 & 100 & 100 \\
OVERALL SPECIFICTY & 100 & 100 & 100 \\
OVERALL ACCURACY & 100 & 100 & 100
\end{tabular}

The sensitivity for $0 \mathrm{KM}, 1000 \mathrm{KM}, 2000 \mathrm{KM}$ and $3000 \mathrm{KM}$ shows the value of 1.00 respectively. For the specificity, it also shows the evaluation value of 1.00 respectively for each oil sample. Meanwhile, the result for accuracy shows 1.00 for each sample. The value 1.00 that was obtained from the calculation represent $100 \%$. Thus, sensitivity, specificity and accuracy for each sample shows $100 \%$ of sensitivity, specificity and accuracy for each sample for $\mathrm{K}=1, \mathrm{~K}=2$ and $\mathrm{K}=3$ respectively. The overall sensitivity, specificity and accuracy shows the $100 \%$ for lubricant oil sample classification using the CBR classification technique.

\section{CONCLUSION}

This study demonstrates that 4 lubricant oil samples which are $0 \mathrm{KM}, 1000 \mathrm{KM}, 2000 \mathrm{KM}$ and $3000 \mathrm{KM}$ have a different odor between each other. The differences of adulteration between samples were caused by the changes of chemical properties of the oil influenced the changes of aroma and odor-profile of the samples. The lubricant oil sample can be classified even though the patterns and the aroma slightly similar between each sample. This is the significant ability that CBR has, which is the classifier technique manages to make classification, even though the source cases that stored in the memory consist of small dimension of data. The classification of lubricant oil sample odor-profile using case-based reasoning classification technique has successfully achieved $100 \%$ classification.

\section{ACKNOWLEDGEMENTS}

The authors would like to thank to Faculty of Electrical and Electronics Engineering and Automotive Engineering Center (AEC) of Universiti Malaysia Pahang for the chances and support for this research. 


\section{REFERENCES}

[1] Rosli M. The automobile industry and performance of Malaysian auto production. Journal of Economic Cooperation among Islamic Countries, 2006, 27(1):89-114

[2] Aly A A, Salem F A. Vehicle suspension systems control: A review. International Journal of Control, Automation and Systems, 2013, 2(2):46-54

[3] Okeke E U, Lebele-Alawa B T. Modification design of petrol engine for alternative fuelling using compressed natural gas. International Journal of Engineering and Technology Innovation, 2013, 3(2):86-94

[4] Orłowicz A W, Mróz M, Tupaj M, Trytek A. Materials used in the automotive industry. Archives of Foundry Engineering, 2015, 15(2):75-78

[5] Mensah-Brown H. Re-refining and recycling of used lubricating oil: An option for foreign exchange and natural resource conservation in Ghana. ARPN Journal of Engineering and Applied Sciences, 2015, 10(2):797-801

[6] Mu T, Chen S, Zhang Y, Guo P, Chen H, Meng F. Motor oil classification based on time-resolved fluorescence. Plos One, 2014, 9(7):1-6

[7] Kamal R S, Ahmed N S, Nasser A M. Study the efficiency of some compounds as lubricating oil additives. Applied Petrochemical Research, 2013, 3(1-2):1-8

[8] Perić S, Nedić B, Grkić A. Applicative monitoring of vehicles engine oil. Tribology in Industry, 2014, 36(3):308-315

[9] Yunus S, Rashid A A, Latip S A, Abdullah N R, Ahmad M A, Abdullah A H. Comparative study of used and unused engine oil (Perodua Genuine and Castrol Magnatec Oil) based on Property Analysis Basis. Procedia Engineering, 2013, 68:326-330

[10] Lara R F, Azcarate S M, Cantarelli M Á, Orozco I M, Caroprese M E, Savio M, Camiña J M. Lubricant quality control: A chemometric approach to assess wear engine in heavy machines. Tribology International, 2015, 86:36-41

[11] Srikanth P, Somasekhar S A, Kanthi G K, Babu K R. Analysis of heavy metals by using atomic absorption spectro-scopy from the samples taken around Visakhapatnam. International Journal of Environment, Ecology, 2013, 3(1), 127-132

[12] Voica C, Kovacs M H, Dehelean A, Ristoiu D, Iordache A. ICP-MS determinations of 
heavy metals in surface waters from Transylvania. Romanian Journal of Physics, 2012, 57(6-7):1184-1193

[13] Capone S, Zuppa M, Montagna G, Siciliano P, Distante C, Caione F, Carlucci A P. Application of a gas sensors array to the detection of fuel as contamination defect in engine oil. In IEEE Sensors, 2008, pp. 442-445

[14] Lu Y, Kippler M, Harari F, Grandér M, Palm B, Nordqvist H, Vahter M. Alkali dilution of blood samples for high throughput ICP-MS analysis-Comparison with acid digestion. Clinical Biochemistry, 2015, 48(3):140-147

[15] Najib M S, Zamberan N H, Zahed N, Halim F A, Zahari M F, Mamat W M, Manap H. Fish quality study using odor-profile case-based reasoning (Cbr) classification technique. ARPN Journal of Engineering and Applied Sciences, 2016, 11(10):1-6

[16] Zahari M F, Julius T A, Halim F A, Najib M S, Ghazali K H, Azoddein A A. Intelligent classification hazardous gas using sensors array. Journal of Advances in Information Technology, 2015, 6(4):233-237

[17] Zohora S E, Srivastava A K, Dey N. Gas Sensing techniques in electronic nose and its applications: A review. In 3rd International Conference of Electrical, Electronics, Engineering Trends. Communication, Optimization and Sciences, 2016, pp. 178-183

[18] Morvan M, Talou T, Gaset A, Beziau J F. Electronic-nose systems for control quality applications in automotive industry. Sensors and Actuators B: Chemical, 2000, 69(3):384-388 [19] Zahed N, Najib M S, Fatin N, Nik N, Azhani M. Classification of honey odor-profile using case-based reasoning technique (Cbr). ARPN Journal of Engineering and Applied Sciences, 2016, 11(10):6675-6679

[20] Najib M S, Ahmad M U, Funk P, Taib M N, Ali N A. Agarwood classification: A Case-Based Reasoning approach based on E-nose. In IEEE 8th International Colloquium on Signal Processing and Its Applications, 2012, pp. 120-126

[21] Recio-García J A, González-Calero P A, Díaz-Agudo B. jcolibri2: A framework for building Case-based reasoning systems. Science of Computer Programming, 2014, 79:126-145

[22] De Soto B G, Adey B T. Investigation of the case-based reasoning retrieval process to 
estimate resources in construction projects. Procedia Engineering, 2015, 123:169-181

[23] De Renzis A, Garriga M, Flores A, Cechich A, Zunino A. Case-based reasoning for web service discovery and selection. Electronic Notes in Theoretical Computer Science, 2016, $321: 89-112$

[24] Mohammed M A, Al-Khateeb B, Ibrahim D A. Case based reasoning shell framework as decision support tool. Indian Journal of Science and Technology, 2016, 9(42):1-8

[25] Zima K. The Case-Based Reasoning model of cost estimation at the preliminary stage of a construction project. Procedia Engineering, 2015, 122:57-64

\section{How to cite this article:}

Daud SM, Najib MS, Zahed N, Jusof MFM, Jusoh@Yusoff MFC, Hassim MIIN. Classification of lubricant oil adulteration level using case-based reasoning. J. Fundam. Appl. Sci., 2017, 9(4S), 256-275. 